\title{
Review of the book Politics under the Influence. Vodka and Public Policy in Putin's Russia by Anna L. Bailey
}

\author{
Jacek Moskalewicz
}

Department of Studies on Alcoholism and Drug Dependence, Institute of Psychiatry and Neurology, Warsaw, Poland

ADDRESS FOR CORRESPONDENCE: Jacek Moskalewicz, Ph.D., Department of Studies on Alcoholism and Drug Dependence, Institute of Psychiatry and Neurology, 9 Sobieskiego Str., 02-957 Warsaw, Poland, e-mail: moskalew@ipin.edu.pl

The book's catchy title, as well as the 'sexy' titles of individual chapters, sometimes go beyond scientific neutrality [1]. For example, Chapter 5 is entitled "The judo gang: informal networks and perception of powers". This suggests the author's critical attitude towards 'Putin's Russia, and could be viewed as a source of potential bias in her analysis.

Nevertheless, the book reads very well and brings together thousands of facts, documents and opinions that decipher the somewhat mysterious aspects of Russian alcohol consumption and alcohol policies against the backdrop of the country's general politics. In addition to a detailed description of contemporary developments, a historical overview is offered, spanning from the prohibition imposed by the Tsar around the First World War and continued in Soviet Russia until the late 1920s, through the notorious attempts to reduce alcohol consumption and related problems in consecutive decades, up to the anti-alcohol crusade initiated by Gorbachev in the mid-1980s. As in the United States, where alcohol policy had been shaped in the shadow of the Prohibition and reduced to individual controls for decades after its repeal, Gorbachev's crusade discouraged any attempts to control alcohol supply in the 1990s. Russia's rapid transition to a market economy also eliminated alcohol control policies from the available repertoire of policy options. Alcohol control policies were rejected as a symbol of Soviet times when the State could interfere in all spheres of life of its citizens including their most private and intimate habit of vodka drinking.

During the very first years of political and economic transition in Russia, the alcohol market, like all markets in general, underwent extreme deregulation. Alcohol became available round-the-clock in thousands and thousands of outlets, not only in shops and bars but also in kiosks and non-stationary outlets that mushroomed across the country. The lion's share of alcohol consumed in Russia consisted of unregistered spirits produced by domestic and foreign companies, which deprived the State budget of substantial revenues. Affordability of vodka further increased as its prices diminished substantially, while the prices of other consumer goods sky-rocketed. The high tide of alcohol consumption was followed by a wave of detrimental effects on public health and safety. According to various estimates, the liberalisation of alcohol supply and access in the 1990s led to an acute demographic crisis in Russia which resulted in several million premature deaths among working (and drinking)-age men, and a drop in male life expectancy to 58 years. Despite the alarming statistics and research reports and publications by domestic and foreign experts warning that the mortality crisis was caused by extremely high levels of overall alcohol consumption, the authorities seemed to attribute it to the poor quality of illicit products.

The author stresses the uniqueness of the Russian case and ignores the fact that similar developments took place in the neighbouring countries, including the Baltic states, Belarus, and Ukraine. In all of them, the alcohol market after the collapse of the Soviet Union (USSR) was rapidly deregulated and consumption increased. While all of them suffered acute mortality crises of a lesser magnitude than Russia, their male life expectancy nonetheless dropped by several years, falling to levels previously observed after the Second World War. For the Polish reader, it is worthwhile remembering that a sig- 
nificant deregulation of the alcohol market also occurred in Poland. Fortunately, however, in the Polish case the resulting alcohol-related mortality crisis was shorter and less dramatic than in the neighbouring countries that used to be part of the USSR. Nevertheless, death rates due to alcohol-related causes in Poland doubled almost overnight at the beginning of the 1990s compared to the 1980 s, and remained at that high level until recently.

According to the author, another specific feature of the Russian attitude towards alcohol is what she calls 'doublethink', or ambivalence both on the individual and the policy levels. This is well illustrated by the Soviet-era joke: 'we think Lenin, we say Party, we say Lenin, we think Party. It has been like that for 70 years - we think one thing and we say another.'

In fact, these discrepant attitudes towards alcohol prevail in most societies where alcohol is consumed. This is due to the combination of positive and negative consequences of drinking, as well as the benefits and harms produced by alcohol at societal and economic levels. Alcohol statistics were treated as confidential not only in the USSR but also in countries with very different politi$\mathrm{cal}$ and economic systems. For example, the first British report on alcohol and health produced in the late 1970s, entitled "Alcohol - our favourite drug", was first printed as confidential with the stamp 'classified' on each of its pages.

The first period of the deregulation of the alcohol market in Russia was associated not only with a health crisis, but also with huge losses to the state revenues. As the author puts it, the State announced a 'hunger strike' in collecting its alcohol revenues. The control over alcohol supply was in practice suspended and numerous institutions were given the privilege of tax-free imports of alcohol and cigarettes. Such a privilege was offered, for example, to the Association of the Veterans of the Afghan War, to various sport unions, e.g. the National Hockey Union, and to the Orthodox Church. However, it is worth mentioning that similar tax exceptions were given in Poland to the Catholic Church, and that tax evasion was seen as a necessary evil in accelerating the primary accumulation of capital throughout the transition period.

After a few years of this laissez-faire approach, the Russian state, facing a substantial budget gap, decided to re-regulate the alcohol market. Tax privileges were withdrawn and more control was exerted over alcohol supply, production, and import. In addition to saving budget revenues, the new policy had the hidden agenda of protecting legal alcohol producers against unfair competition from the black market. After all, in the official narratives the source of the soaring alcohol-related mortality rates was not the high consumption of alcohol per se, but rather the supply and consumption of low quality illicit alcohol specifically.

This attempt at re-regulation was partially successful, and the black market competitors began to disappear from the alcohol arena already in the last days of Boris Yeltsin's presidency and in the early days of Putin's rule. The battle for the alcohol market was prolonged, but in the end legal vodka producers prevailed. To reduce the number of market competitors, and to secure the position of the large producers (which often belonged to the informal network of oligarchs associated with the ruling elite), a special state licensing body was established, which enforced high production and storage standards which eliminated smaller producers who were not able to meet these requirements

In addition to the struggle for domination on the vodka market, a new competitor appeared in the late 1990s, namely the brewers. As shown in the book, beer consumption increased six-fold between 1996 and 2006, with per capita consumption rising from 15 litres in 1996 to 80 litres in 2006 . In a relatively short period, Russia transformed into the third biggest beer market in the world. The rising fortunes of beer could be attributed to the emergence in Russia of a strong lobby representing the huge multinational brewing companies. Their greatest success in the late 1990s was to secure the classification of beer as a non-alcoholic beverage. This way beer became exempted from most of the controls applied to alcoholic beverages. The multinationals astutely exploited the argument of public health advocates that one of the ways to reduce alcoholism in Russia was to reorient consumption towards beverages with a lower alcohol content. Thus, the favourable legal status of beer, including the ability to advertise it, could be interpreted as a measure in favour of public health interests.

This feature of alcohol policy in Russia is also not exceptional from the global perspective. Globally, the share of beer in the volume of alcohol consumed has been on the rise. In fact, in many countries beer received a privileged legal position as compared to other alcoholic beverages. A very similar strategy was applied by the beer lobby in Poland in the early 1990s. Thanks to a successful lobbying campaign, beer was exempted from most of the controls applied to beverages containing more that $4.5 \%$ alcohol. As a result, beer consumption in about 20 years increased from 30 litres to almost 100 litres per capita, while its share in overall alcohol consumption approached $60 \%$.

Unlike in Poland, where beer still enjoys a privileged position, countermeasures were taken in Russia to slow its progression as soon as the foreign-owned brewing industry emerged as a strong competitor to the vodka industry with all its connections with the ruling elites. The battle on the alcohol arena extended from being a confrontation between different vodka suppliers, and also involved the beer industry. Beer became increasingly portrayed as an enemy of public health by representatives of anti-beer lobbies, who claimed that beer dependence is even worse than vodka dependence. For example, it was claimed that beer affects males in 
reproductive age by increasing female hormones in their bodies. Attempts were made to subordinate beer production to a licensing system, as well as to an electronic system of production surveillance which was in force for spirits.

The Russian 'alcohol story' was initially dominated by economic interests, first of all of private producers and suppliers, but also the economic interest of the State. Later it extended to include also anti-alcohol movements concerned with the substantial deterioration of population health in Russia. These movements were conceived among Russian elites supported by important individuals in the Russian Orthodox Church. Their attempts were accompanied by a growing awareness that the demographic crisis, accelerated by alcohol-related mortality, put at risk the future of Russia as a state due to the decline in its population.

These risks were taken seriously by Putin's administration. A debate was launched on how to reverse these dangerous tendencies. The official narratives changed from a focus on illicit, low-quality alcohol to overall per capita consumption. During the Medvedev presidency alcohol was labelled a 'national disaster', and a serious threat to the national development. Instructions were given to draft a far-reaching alcohol control programme and legislation. The debate that followed proved that the political system in Russia is not as omnipotent and centralised as is often thought.

Radical anti-alcohol measures that were initially proposed were revised several times, both in inter-ministerial consultations and in the Parliament. Pressure from the alcohol industry also had an impact. In effect, instead of radical changes in alcohol regulation, gradual steps were taken and the process of increasing control over alcohol continued over 3-4 years. Thanks to the slow pace, the new policies did not produce sudden side-effects which could deteriorate the public image of the reform and in effect deprive it of public support. The reform could be considered effective from the public health point of view if one looks at major indicators such as the rate of death from accidental alcohol poisoning, as well as incidents of alcohol psychosis. Both indicators reached their recent peak around 2006, and continuously declined for the next decade, reflecting declining alcohol consumption.

The author appears surprised that the beginning of this downward trend occurred a few years before real changes in alcohol control were imposed. It could be argued that alcohol consumption in Russia started to decline due to having reached a point of saturation at the very high level of about 15 litres per capita at the beginning of the $21^{\text {st }}$ century. Moreover, from January 2006 an efficient electronic system of surveillance of spirits production was implemented that could have contributed to reducing the amount of unrecorded spirits flooding the Russian market in earlier years. Finally, the campaign against 'beer alcoholism' was initiated at about that time, tarnishing the image of beer and curbing further increases in beer production and consumption. Less than two years later the financial crisis that severely hit Russia led to declines in real incomes. In consequence, alcohol became less affordable, with all the resulting positive effects for public health. During the years of recovery from the economic crisis further steps were taken in the area of alcohol control that reinforced and perpetuated earlier positive trends.

Ending my review, I would like to stress again that the book is most certainly a worthwhile read. Despite its idiosyncrasies, the lessons drawn from the attempts to reduce alcohol consumption in Russia should be carefully studied by researchers as well as by policy makers outside Russia. Neglecting the risks associated with alcohol consumption, and reckless policies in this field, can have disastrous consequences for public health and order, as well as for social and political development in general.

\section{DISCLOSURE}

The author reports no conflict of interest.

\section{References}

1. Bailey AL. Politics under the influence. Vodka and public policy in Putin's Russia. Cornell University Press, Ithaca and London 2018.

Jacek Moskalewicz, Ph.D., sociologist, head of the Department of Studies on Alcoholism and Drug Dependence at the Institute of Psychiatry and Neurology in Warsaw, Poland. Member of the WHO experts' advisory panel on drug dependence and alcohol problems. In 2009-2015 deputy-chairman of the Science Group of the EC Alcohol and Health Forum. Recipient of Jellinek Memorial Award (2001) and Chevalier Cross of Polonia Restituta (2004). 